\title{
ASPECTOS DO DESIGN UNIVERSAL: uma proposta de máquina de cartão para deficientes visuais
}

\author{
Roberta Lucas Scatolim \\ Faculdade de Arquitetura, Artes e Comunicação da UNESP - Campus de Bauru \\ professoraroberta@hotmail.com \\ Prof. Dr. João Eduardo Guarnetti dos Santos \\ Faculdade de Arquitetura, Artes e Comunicação da UNESP - Campus de Bauru \\ guarneti@feb.unesp.br \\ Prof. ${ }^{\text {a }}$ Dr ${ }^{\mathrm{a}}$. Paula da Cruz Landim \\ Faculdade de Arquitetura, Artes e Comunicação da UNESP - Campus de Bauru \\ paula@faac.unesp.br
}

\begin{abstract}
Resumo: Esse estudo enfatiza a interface deficiente visual - máquina de cartão de crédito e débito. A proposta é estudar soluções de design, com referências pertinentes e relevantes, para adaptar a informação em áudio, aumento das proteções laterais e teclas em Braille, com o objetivo de facilitar a usabilidade dos deficientes visuais em seu cotidiano. Ressalta a importância do design, sobretudo o Design Universal, como um mediador que garante o acesso à informação e a praticidade dos usuários, principalmente aqueles que têm dificuldade ou restrição e uso. Essa pesquisa propõe um projeto de máquina de cartão acessível para quem não enxerga, com pequenas alterações em seu design.
\end{abstract}

Palavras-chave: Design Universal, cartão de crédito, tecnologias assistivas.

\section{INTRODUÇÃO}

No Brasil, existem mais de 6,5 milhões de pessoas com deficiência visual, sendo 582 mil cegas e 6 milhões com baixa visão, segundo dados do Censo 2010, feito pelo Instituto Brasileiro de Geografia e Estatística (IBGE).

A deficiência visual severa foi a que mais incidiu sobre a população em 2010, $3,5 \%$ das pessoas declararam possuir grande dificuldade ou nenhuma capacidade de enxergar.

O número relevante de usuários que necessitam de outras formas de interações, que vão além do visual, implica em pesquisa e projetos de produtos e serviços capazes de garantir o uso sem restrições, universal.

Estudos sobre o Design Universal se intensificaram depois da Revolução Industrial, com a reflexão sobre os processos produtivos, e ao longo da evolução dos 
produtos, apesar de melhorias na qualidade como uma característica é constante: a importância do Design como mediador para a igualdade de uso.

Esse estudo aponta problemas de acessibilidade nas máquinas de cartão de crédito e propõe soluções para que sejam resolvidos. Não há disponível no mercado uma máquina de cartão que atenda aos portadores de deficiência visual, e percebe-se o uso crescente do cartão pelos usuários, devido à praticidade e a segurança.

A única informação disponível para quem não enxerga é um ponto na tecla no 5, padrão em outros aparelhos de utilidade doméstica, que por ele o usuário tem uma noção espacial para digitar as outras teclas.

Além disso, vemos um problema no design das máquinas de cartão, que afeta também usuários que enxergam, é a exposição das mãos ao digitar, passível de ser observada ao digitar a senha.

O deficiente visual não consegue saber qual valor foi digitado para ser debitado em seu cartão, o que demonstra uma relação de dependência e confiança nessa tarefa.

A interface máquina de cartão - deficiente visual apresenta três problemas importantes:

1- O usuário não consegue saber qual valor será realmente debitado em sua fatura, já que não consegue ver o painel;

2- As teclas não têm código Braille;

3- Enquanto a senha é digitada, outras pessoas podem vê-la, pois não há proteções laterais.

Pretende-se com esse estudo pesquisar o desenvolvimento de uma máquina adaptada de cartão de crédito/débito, que garanta a acessibilidade e a praticidade de uso aos portadores de deficiência visual. Para tanto, a interdisciplinaridade com outras áreas de conhecimento é fundamental, para a coleta de informações e o êxito da pesquisa.

\section{DESENVOLVIMENTO}

Várias áreas do conhecimento podem contribuir para um mundo menos desigual, para que haja a interação social por meio do design universal, como a acessibilidade, o design, a ergonomia e a usabilidade.

A acessibilidade deve garantir a realização de tarefas cotidianas, ou seja, diminuir dificuldades encontradas, permitindo a participação e a independência individual.

Löbach (2001) ressalta soluções cujo produto deixa de ser o objeto central de interesse, e passa a ser um problema social, implicando em etapas projetuais.

A ergonomia contribui para conceder oportunidades aos usuários com distintas potencialidades e limitações. Condições que exigem adaptação de processos, produtos e ambientes, de acordo com premissas físicas, sociais e comportamentais.

As habilidades humanas devem ser consideradas no projeto de produto, sobretudo quando se busca inovar. Martins et al. (2001), defende a junção do design universal à ergonomia, em pesquisa e desenvolvimento, como uma diretriz determinante para a melhoria da qualidade de vida.

Para lida (2005), há semelhança entre os critérios de produto universal e usabilidade, pois o projeto universal torna um produto acessível a todos os usuários, e a usabilidade tem por objetivo facilitar seu uso. "[...] no processo de projeto trata-se 
de estabelecer [conexões] entre os mundos simbólicos dos usuários (ou grupo de usuários) e os produtores de símbolos (as empresas). É necessária uma profunda compreensão dos respectivos mundos simbólicos" (BÜRDEK, 2006, p.325). "Muito embora o designer possa estar envolvido em grande parte do ciclo de vida de um produto, fica claro, a partir da literatura, que a principal contribuição do design de produtos, dentro do contexto produtivo, encontra-se no estágio de desenvolvimento. Nesta etapa, a especialidade do designer está ligada aos aspectos configurativos e comunicativos dos produtos; em relação a questões como ergonomia e produção, o designer insere-se como conhecedor dentre outros especialistas destas áreas". (BÜRDEK, 2006, p.277).

Nesse contexto, podemos afirmar que um produto é otimizado quando se torna acessível à maioria. A usabilidade sem distinções é consequência de um projeto que permite alterações de suas características, para adaptar aos usuários de diferentes habilidades ou necessidades especiais.

\subsection{Aspectos do Design Universal}

A usabilidade implica em facilitar o uso de serviços, produtos e sistemas, tornando tais tarefas fáceis de entender e operar, e diminuindo erros na interface produto-usuário.

Dessa forma, a integração entre acessibilidade, design (universal), ergonomia e usabilidade, possibilita soluções adequadas às reais necessidades dos usuários, em meio às diferentes potencialidades - produtos, sistemas e ambientes.

Os "Princípios do Design Universal", definidos pelo "Center for Universal Design - College of Design" da Universidade do Estado da Carolina do Norte, Estados Unidos, visam criar projetos e processos de produção para trazer produtos e ambientes com melhor usabilidade. Eles são: Uso equitativo: deve garantir a todos os usuários a mesma usabilidade, sem excluir pessoas com necessidades ou deficiências; Flexibilidade no uso: o design deve proporcionar a forma de utilização adequada, com a possibilidade de ser adaptável, com praticidade na utilização; Uso simples e intuitivo: o design deve ser de compreensão fácil, até para usuários inexperientes que tem dificuldade de desempenho. Não deve ser complexo; Informação perceptível: de fácil compreensão a todos os usuários, independentemente das suas dificuldades ou condições de uso; Tolerância ao erro: o design deve minimizar as consequências negativas dos erros de usabilidade; Baixo esforço: possibilitar o uso de um produto com o mínimo de esforço físico e operações repetitivas; Tamanho e espaço adequados: adaptação de espaços, visibilidade e tamanho, para melhorar a mobilidade.

Tais princípios podem ser aplicados a todas as disciplinas de projeto e a todos os usuários. Destinados para avaliar objetos ou ambientes, colaborar com o processo de design, e inserir a cultura da igualdade de uso para empresas, designers e consumidores.

O Design Universal implica no diferencial do projeto, e não como um constrangimento, pois o uso universal representa a não limitação das atividades. Portanto um princípio ético que todos os indivíduos têm o direito ao uso.

Simões e Bispo (2003) propõem estruturar um "Role Playing". Técnicos e responsáveis são convidados a experimentar situações como se fossem portadores 
deficiências. Uma técnica que apresenta resultados para a compreensão dos impactos e soluções de projeto, em busca da acessibilidade e qualidade de vida.

O objetivo do Role Playing é permitir aos participantes vivenciar as dificuldades enfrentadas pelos usuários que tem algum tipo de deficiência. Porém Contudo, essa metodologia pode causar riscos, pois a experiência da deficiência não pode ser totalmente simulada.

O Design Universal é inserido ao projeto por vários argumentos, fatores que apoiam o Design Inclusivo como uma estratégia de um ambiente socioeconomicamente mais sustentável. São argumentos de sustentabilidade; morais, econômicos e sociais; morais, econômicos e sociais; econômicos; e éticos e deontológicos.

O conhecimento das necessidades dos usuários e saber suas expectativas em relação ao produto influi na concepção adequada de projetos.

\subsection{Tecnologias Assistivas}

Novas políticas públicas têm sido geradas na área da acessibilidade, como, por exemplo, Plano Nacional dos Direitos da Pessoa com Deficiência - Viver sem Limite, lançado no dia 17 de novembro de 2011, Decreto № 7.612, do Governo Federal, que destinou 7,6 bilhões de reais, a serem aplicados entre os anos de 2011 e 2014, em ações voltadas aos direitos das pessoas com deficiência.

Produtos desenvolvidos àqueles que possuem necessidades especiais são chamados de Tecnologia Assistiva, seja artesanais ou produzidos em série, é destinado a aperfeiçoar habilidades de pessoas com limitações cognitivas, físicas ou visuais.

O design tem um papel fundamental para resolver problemas do usuário de acordo com o Design Universal, direcionando, de forma horizontal, tecnologias para todas as pessoas.

Portanto, acessibilidade não se restringe apenas ao direito de acessar a rede de informações, mas de utilizar ambientes urbanos, equipamentos e serviços de forma adequada e com independência, para melhor qualidade de vida e inclusão social.

Tecnologia Assistiva - TA são utilizadas para identificar um produto ou serviço, com recursos que contribuem ampliar habilidades funcionais de usuários com deficiência.

Projetar produtos que promovam a inclusão e a acessibilidade, reduzindo diferenças é um dos desafios da Tecnologia Assistiva.

Segundo Bersch (2005), o termo Assistive Technology, Tecnologia Assistiva no Brasil, foi criado oficialmente em 1988 como instrumento jurídico da legislação norte americana, conhecida como Public Law 100-407, que compõe, com outras leis, o ADA American with Disabilities Act..."todo e qualquer item, equipamento ou parte dele, produto ou sistema fabricado em série ou sob medida, utilizado para aumentar, manter ou melhorar as capacidades funcionais das pessoas com deficiência")(BERSCH, 2005, p.3).

Pesquisar sobre a Tecnologia Assistiva no desenvolvimento de produtos exige o aprofundamento em conceitos referentes ao termo. No Brasil, a Secretaria dos Direitos Humanos da Presidência da República (SDH/PR) utiliza o seguinte conceito: Tecnologia Assistiva é uma área do conhecimento, com caráter interdisciplinar, que envolve produtos, recursos, estratégias, metodologias, serviços e práticas, em busca da funcionalidade e a participação de pessoas com deficiência, com limitação ou 
mobilidade reduzida. TA busca a autonomia, a qualidade de vida e inclusão social dos usuários com deficiência (BRASIL, 2012).

Para Hersh e Johnson (2008) existem duas abordagens principais para a deficiência: a médica e a social. A abordagem social refere-se às influências do meio ambiente no projeto, de acordo com experiência dos usuários que possuem limitações físicas e sociais A abordagem médica implica no diagnóstico, na prescrição médica, organizada por pesquisadores na área da saúde.

O aprofundamento sobre as necessidades especiais dos usuários e sua ocupação na sociedade onde atua denota as possibilidades para auxiliar no desenvolvimento de produtos com características assistivas.

\subsection{Contexto histórico do cartão e proposta de uma máquina acessível}

Culturalmente presenciamos a substituição do uso de papel moeda pelos cartões de crédito e débito. Além das instituições financeiras e bancos, lojas oferecem cartões que podem ser usados na compra de bens e serviços, sobretudo em compras virtuais.

Os cartões de crédito surgiram na década de 1920 nos Estados Unidos. Os primeiros a utilizar foram hotéis e postos de gasolina, que os ofereciam aos clientes fiéis, que podiam utilizar esses serviços sem o uso de dinheiro ou cheque.

Em 1950, o Diners Club criou o primeiro cartão de crédito, aceito em 27 bons restaurantes e usado apenas por grandes empresários. Esse cartão foi confeccionado em papel cartão, trazia o nome do associado de um lado e dos estabelecimentos filiados em outro. Somente em 1955 o Diners passou a usar o plástico em sua fabricação.

Em 1958, o American Express lançou o seu cartão, e no mesmo ano o Bank of America introduziu o seu Bank Americard, que se denominou Visa. E na década de 1990, o Visa tornou-se o maior cartão com circulação mundial, aceito em 12 milhões de estabelecimentos.

No fim da década de 1990, o Brasil adquiriu o cartão com chip, um dispositivo que deu trouxe mais segurança para empresas e usuários.

A Figura 1 ilustra a antiga máquina de cartão da Visa. Antes, quando a compra era feita por cartão, se usava o papel carbono, o cartão de crédito ficava registrado em relevo, e havia a possibilidade de fraude.

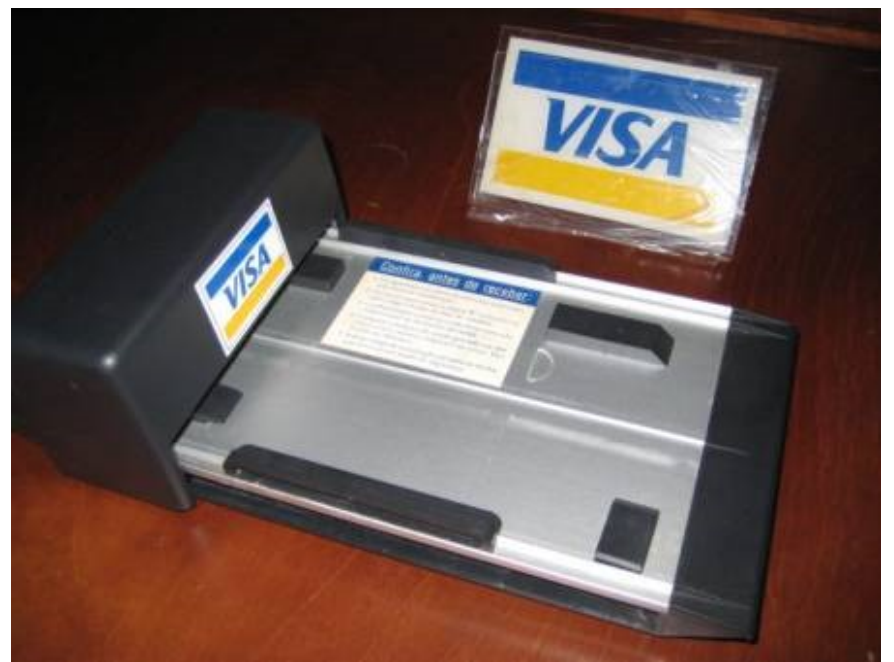

Figura 1 - Antiga maquina de cartão credito Visa. Fonte: Classificados Viva Street. 
Com chip e senha, as compras de produtos e serviços tornaram-se mais seguras e práticas, sobretudo, nas aquisições virtuais, e-commerce.

O designer Kwon Ki Nam desenvolveu um conceito de cartão de crédito dirigido aos cegos ou pessoas com baixa visão, como mostra a Figura 2. Um dispositivo com tecnologias de biometria (reconhecimento de impressão digital) e alfabeto apropriado para a leitura (Braille). O monitor (em Braille) disponibilizaria os detalhes da transação (em vez de imprimir um comprovante).

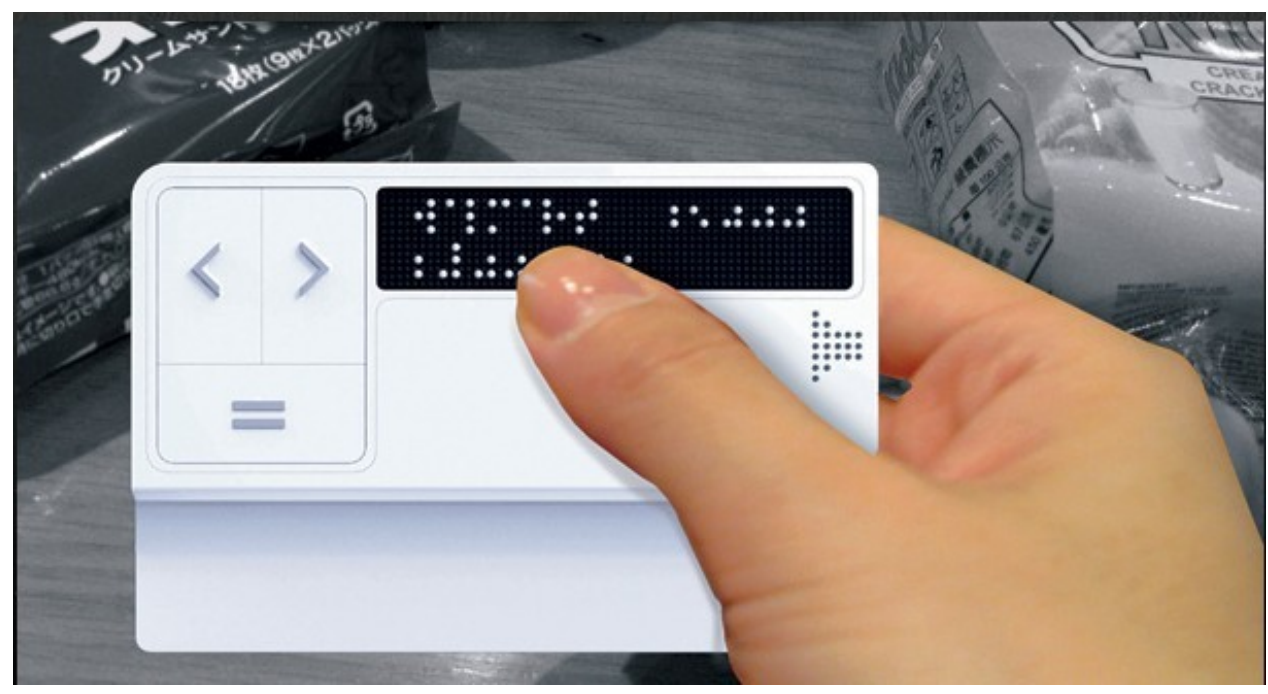

Figura 2 - Cartão de crédito com Braille. Fonte: Site Tecmundo.

Nas compras, um áudio embutido especifica ao usuário os produtos listados para a aquisição. Mas esse sistema ainda não está disponível, o que dificulta transações comerciais nas compras com cartão para quem não vê.

A Resolução no 47, de 3 de agosto de 2006, da Secretaria Especial dos Direitos Humanos, Conselho Nacional dos Direitos da Pessoa Portadora de Deficiência Presidência da República, que dispõe sobre cartão de crédito para portadores de deficiência, propõe várias medidas a serem adotadas pelas empresas emissoras de cartão de crédito no atendimento às pessoas com deficiência.

Segundo essa resolução cabe às empresas emissoras de cartão de crédito adaptar procedimentos e cartões para o acesso e utilização por pessoas com deficiência visual e auditiva.

Para os deficientes visuais, essa resolução determina que o usuário tenha condições de identificar a bandeira do cartão em Braille, em campo distinto da tarja magnética, e instalados postos de autoatendimento com circuito sonoro e fone de ouvido, para viabilizar o acesso à senha alfanumérica de localização variável na tela. Nesse contexto, segue uma proposta de máquina acessível àqueles que não podem enxergar, conforme a Figura 3. 


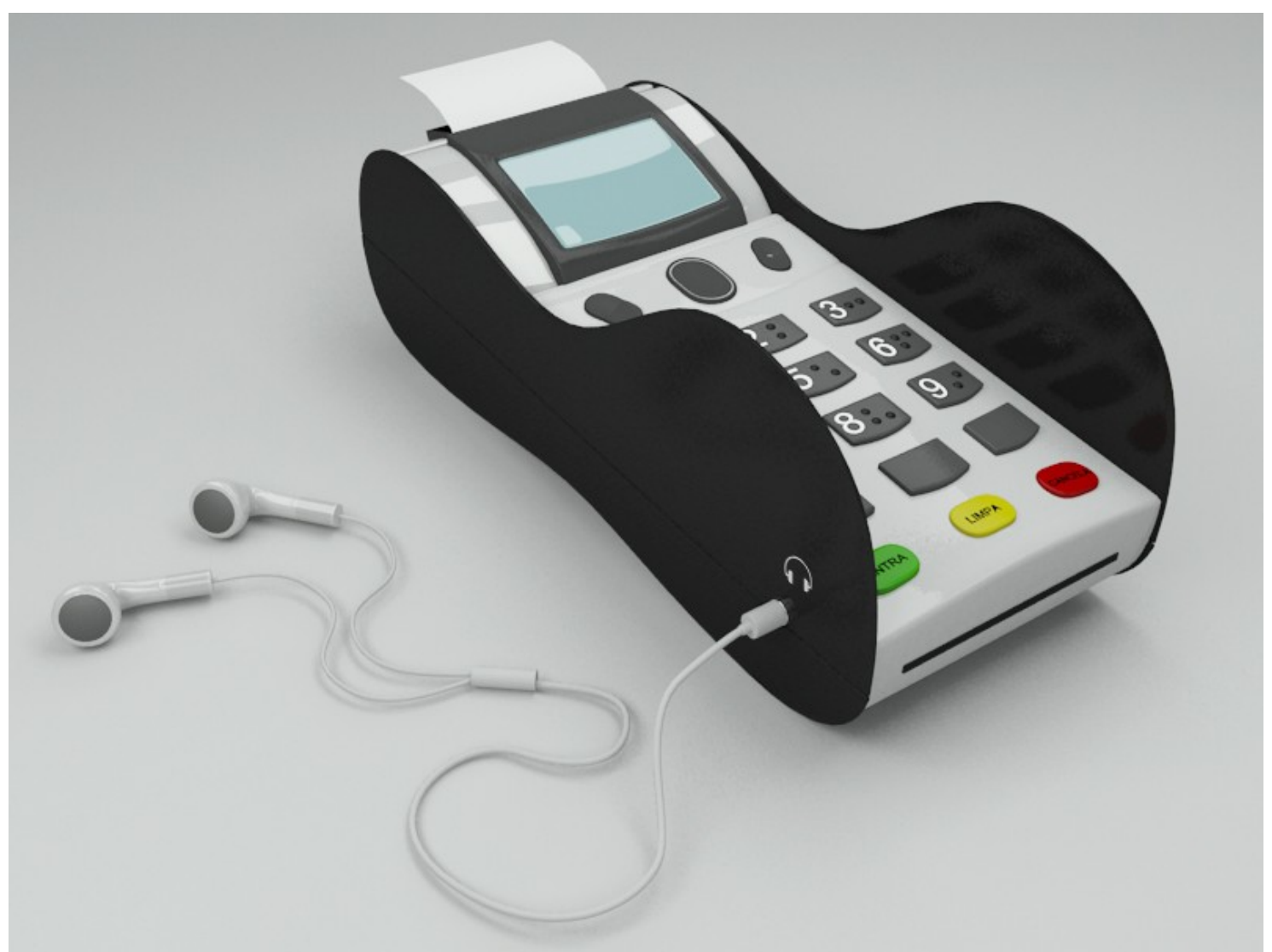

Figura 3- Máquina de cartão com áudio. Desenho: Guilherme Paviani.

A proposta é inserir pequenas mudanças na máquina de cartão para torna-la acessível aos portadores de deficiência visual.

As máquinas de cartão existentes no mercado limitam quem não pode enxergar, dessa forma a proposta é uma máquina com áudio, para que se ouça o valor que será debitado, inserir o código Braille nas teclas e aumentar as proteções laterais para que outras pessoas não vejam o número da senha digitada.

Tais mudanças trariam mais segurança e independência dos usuários cegos, que dependem de terceiros para executar essa atividade.

"As tecnologias intelectuais ocupam o lugar de auxiliares cognitivos dos processos controlados, aqueles que envolvem a atenção consciente e dispõem de tão poucos recursos no sistema cognitivo humano. Dessa forma, as tecnologias intelectuais servem como paliativo para certas fraquezas dos processos automáticos como as heurísticas de raciocínio e os mecanismos esquematizados da memória de longo prazo." (LÉVY, 1993, p. 92).

\section{CONCLUSÃO}

Considerando o relevante número usuários com deficiência visual, de acordo com dados do IBGE, percebemos a necessidade crescente de projetos e produtos acessíveis.

Pensar o desenvolvimento de uma máquina adaptada de cartão de crédito/débito é estimular a acessibilidade e a praticidade.

O design é um mediador do acesso sem restrição e da inclusão social, e consequentemente, a usabilidade não pode ser um fator que distingue quem pode ou não utilizar produtos e serviços. 
Dessa forma, projetos devem permitir alterações adaptadas as dos usuários, sobretudo as necessidades especiais.

Para garantir as adequações pertinentes, o Design Universal e as Tecnologias Assistivas são fundamentais para aumentar as habilidades funcionais de usuários especiais.

Projetar produtos que ampliem a inclusão e a acessibilidade, e que diminuem diferenças são características que deveriam estar intrínsecas em qualquer projeto.

Acreditamos que tais modificações nas máquinas de cartão são relevantes para eliminar a restrição de uso, de um objeto cotidiano, porém, ainda inacessível.

\section{REFERÊNCIAS}

ALBERTIN, Alberto Luiz; MOURA, Rosa Maria de. Comércio eletrônico: seus aspectos de segurança e privacidade. Rev. adm. empres. [online]. Vol.38, n.2, 1998. P. 49-61.

ALENCAR, Eunice M. L. Soriano de. Criatividade. 2. ed. Brasília: Editora UnB, 1995.

BANCO CENTRAL DO BRASIL. Museu de Valores do Banco Central: cartões de crédito. Disponível em: <http://www.bc.gov.br/?HISTCARTAO> Acesso em 14 mai. 2012

BAXTER, Mike. Projeto de produto: guia prático para o design de novos produtos. 2. ed. rev. São Paulo: Blücher, 2000.

BERSCH, Rita; TONOLLI, José Carlos. Assistive Technology Applications Certificate Program / CSUN California State University - Northridge - EUA. Disponível em: <www.cedionline.com.br> Acesso em 28 ago. 2013

BONSIEPE, Gui. A tecnologia da tecnologia. São Paulo: Blücher, 1983.

BRASIL, IBGE. Censo demográfico, 2010. Disponível em: <http://www.sidra.ibge.gov.br/bda/tabela/listabl.asp?c=3326\&z=cd\&o=7>. Acesso em 17 abr. 2012

BÜRDEK, Bernhard E. História, teoria e prática do design de produtos. São Paulo: Blücher, 2006.

CIELO. Terminais Eletrônicos. Disponível em: <http://www.cielo.com.br/portal/cielo/solucoes-de-tecnologia/terminaiseletronicos.html> Acesso em 28 mai. 2012

CMDV, Portal do Deficiente Visual. Cartão de Crédito para Portadores de Deficiência. Disponível em: <http://www.cmdv.com.br/lermais_materias.php?cd_materias=315> Acesso em 12 mai. 2012

EXAME INFO. Redecard testa pagamento por celular. Disponível em: $<$ http://info.abril.com.br/noticias/corporate/redecard-testa-pagamento-por-celular23092010-43.shl> Acesso em 28 mai. 2012

GALVÃO, Teófilo Filho. A Construção do Conceito de Tecnologia Assistiva: Alguns Novos Interrogantes a Desafios. Disponível em: <http://www.planetaeducacao.com.br/portal/artigo.asp?artigo=2430> Acesso em 02 mar. 2014 
GERTEC. Pin $\quad$ Pad $\quad$ PPC 900. Disponível em <http://www.gertec.com.br/produto.aspx/produtosdetalhe/23/PPC_900> Acesso em 28 mai. 2012

GLOBO, Universidades. Cartões, celulares e chips assumem lugar do dinheiro físico em compras. Disponível em: <http://redeglobo.globo.com/globouniversidade/noticia/2012/03/cartoes-celulares-echips-assumem-lugar-do-dinheiro-fisico-em-compras.html> Acesso em 21 mai. 2012

HERSH, M.; JOHNSON, M. On modeling assistive technology systems - Part I: Modelling framework. Technology and Disability 20, IOS Press, 2008.

IBGE. Instituto Brasileiro de Geografia e Estatística. Censo Demográfico 2010. Disponível em: <http://www.ibge.gov.br/home/presidencia/noticias/noticia_visualiza.php? id_noticia=2018\&id_pagina=1> Acesso em 02 mai.2012 IIDA, Itiro. Ergonomia: Projeto e Produção. 2. ed. São Paulo: Blücher, 2005.

LÉVY, Pierre. As tecnologias da inteligência: o futuro do pensamento na era da informática. Trad. Carlos Irineu da Costa. Rio de Janeiro: Editora 34, 1993.

LÖBACH, B. Design Industrial: bases para a configuração dos produtos industriais. São Paulo: Edgard Blücher, 2001.

MARTINS, L.B. et. al. Sistema de Informação e Design Universal - Garantia de Acessibilidade. In: Seminário Acessibilidade, Tecnologia da Informação e Inclusão Digital, 1., 2001, São Paulo. Anais eletrônicos do I Seminário Acessibilidade, Tecnologia da Informação e Inclusão Digital. São Paulo: USP, 2001. Disponível em: <http://www.fsp.usp.br/acessibilidade>. Acesso em 04 mar. 2014.

REVISTA TECNOLOGIA GRÁFICA. Todas as fases de produção dos cartões plásticos. Disponível em: <http://www.revistatecnologiagrafica.com.br/index.php? option=com_content\&view=article\&id=273:todas-as-fases-de-producao-dos-cartoesplasticos\&catid=39:impressao\&ltemid=180> Acesso em 23 mi. 2012

SIMÕES, Jorge Falcato; BISPO, Renato. Manual de apoio às acções de formação do projecto Design Inclusivo. Iniciativa EQUAL Edição da Divisão de Formação da Câmara Municipal de Lisboa, Lisboa, Setembro 2003.

TECMUNDO. Designer cria conceito de cartão de crédito para cegos. Dispositivo facilitaria o processo de efetuar transações para os portadores de necessidades especiais relacionadas à visão. Disponível em: <http://www.tecmundo.com.br/6347designer-cria-conceito-de-cartao-de-credito-para-cegos.htm\#ixzz1vB6JIzf3> Acesso em 17 mai. 2012

VIVA STREET. Classificados: Antiga maquina de cartão credito Visa. Disponível em: $<$ http://compra-venda-colecao.vivastreet.com.br/artigos-decolecionador+ipiranga/antiga-maquina-de-cartao-credito-visa-semuso/45662736\#annonce> Acesso em 31 mai. 2012 